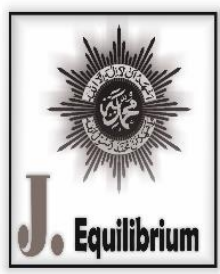

Equilibrium: Jurnal Pendidikan

Vol. VIII. Issu 2. Juni-Desember 2020

Prodi Pendidikan Sosiologi

http://journal.unismuh.ac.id/index.php/equilibrium

\title{
Optimalisasi Peran Dasawisma Dalam Menurunkan Angka Kematian Bayi di Desa Pukat Kecamatan Utan
}

\author{
Aya Shofia ${ }^{1}$ \\ ${ }^{1}$ Manajemen Inovasi, Universitas Teknologi Sumbawa, Indonesia \\ Email: ayashofia99@yahoo.com
}

\begin{abstract}
This research describes the conditions of the dasawisma in the village Pukat subdistrict Utan and describes the role of the dasawisma in lowering the infant mortality rate in the village Pukat subdistrict Utan. The research approach is quantitatively with comparative research methodology comparing the role of the dasawisma in the village of Orong Bawa and Pukat villages, with data collection techniques through interviews, observations and questionnaire. The results showed that after the role of optimisation strategy in the village of Pukat, the infant mortality rate decreased from 6 infant mortality rates in 75 infants born in the period of January to June 2018 to 1 infant mortality rate from 64 babies born alive in the period of January to June 2019 . The conclusion of this research is some causes of high mortality rates in the village Pukat, among others: the level of knowledge of pregnant women who are dominant elementary and not school, government support and communities that are still lacking and the role of The PKK Tim and the dasawisma group lack maximum functioning.
\end{abstract}

Keywords: infant mortality rate, dasawisma, optimisation, role

Abstrak. Penelitian ini mendeskripsikan kondisi kepengurusan dasawisma di Desa Pukat Kecamatan Utan dan mendeskripsikan peran dasawisma dalam menurunkan angka kematian bayi di Desa Pukat Kecamatan Utan. Pendekatan penelitian yang dilakukan adalah kuantitaif dengan metodologi penelitian komparatif yang membandingkan peranan dasawisma di Desa Orong Bawa dan Desa Pukat, dengan teknik pengumpulan data melalui Wawancara, observasi dan kuisioner. Hasil Penelitian menunjukkan bahwa setelah dilakukan strategistrategi optimalisasi peran dasawisma di Desa Pukat, angka kematian bayi menurun dari 6 angka kematian bayi pada 75 bayi lahir hidup periode Januari sampai Juni 2018 menjadi 1 angka kematian bayi dari 64 bayi lahir hidup pada periode Januari sampai Juni 2019. Kesimpulan dari penelitian ini adalah beberapa penyebab tingginya angka kematian bayi di Desa Pukat diantaranya: tingkat pengetahuan ibu hamil yang dominan Sekolah Dasar dan Tidak Sekolah, dukungan pemerintah dan masyarakat yang masih kurang serta peran Tim Penggerak PKK dan kelompok Dasawisma kurang berfungsi secara maksimal.

Kata Kunci : Angka Kematian Bayi, Dasawisma, Optimalisasi, Peran

\section{PENDAHULUAN}

Berdasarkan profil kesehatan Kabupaten Sumbawa tahun 2014 - 2018, Angka Kematian Bayi dari tahun 2014 sampai tahun 2018 mengalami penurunan yaitu dari 73 kasus di tahun 2014 turun menjadi 65 kasus kematian bayi di Tahun 2018. Sedangkan di Kecamatan Utan angka kematian bayi terus mengalami peningkatan Pada tahun 2014 angka kematian bayi 7 kasus, tahun 2015 terjadi 9 kasus, tahun 2016 terjadi 12 kasus, tahun 2017 terjadi 16 kasus dan pada puncaknya tahun 2018 sebanyak 33 kasus kematian bayi. Hal ini tentu saja sangat memperihatinkan untuk itu diperlukan perhatian seluruh stakeholder yang terkait, mulai dari Pemerintah Desa beserta Lembaga Kemasyarakatannya dan Tim Penggerak PKK desa dengan dasawismanya. Pemerintah Kecamatan dengan berkoordinasi lintas sektor terkait dan juga Tim Penggerak PKK Kecamatan yang akan 
mendukung dan membina Tim Penggerak PKK Desa agar lebih maksimal dalam pelaksanaan peran dan fungsinya.

Berdasarkan evaluasi program Kesehatan Ibu dan Anak (KIA) Se Kecamatan Utan Periode Januari sampai dengan bulan Oktober tahun 2018, angka kematian bayi yang berjumlah 37 orang tersebar di 7 Desa di Kecamatan Utan dari 9 desa yang ada. 7 desa tersebut adalah Desa Jorok sebanyak 10 orang, Desa Pukat sebanyak 9 orang, Desa Bale Berang sebanyak 2 orang, Desa Motong sebanyak 7 orang, Desa Stowe Brang sebanyak 6 orang, Desa Labuan Bajo 2 orang dan Desa Sabedo 1 orang. Sedangkan 2 desa dengan 0 angka kematian bayinya adalah Desa Orongbawa dan Desa Tengah.

Dari data diatas dapat dilihat ada 3 Desa yang memiliki tingkat kematian bayi yang cukup tinggi yaitu Desa Jorok, Desa Pukat, dan Desa Motong. Sedangkan ada 2 desa yang jumlah angka kematian bayinya 0 yaitu Desa Tengah dan Desa Orong Bawa. Desa - desa yang memiliki angka kematian bayi tinggi ini memiliki luas wilayah yang cukup luas dan jumlah penduduk yang sangat besar sedangkan desa yang angka kematiannya 0 memiliki luas wilayah yang lebih sempit dan jumlah penduduk yang sedikit pula.

Tim Pengerak Pemberdayaan Kesejahtraan Keluarga (TP. PKK) dapat berperan aktif dalam menurunkan angka kematian bayi, sesuai dengan Peraturan Presiden No. 99 tahun 2018 tentang Gerakan Pemberdayaan dan Kesejahtraan Keluarga. Peran Tim Pengerak PKK dalam menekan angka kematian bayi dapat melalui Kelompok dasar PKK di Desa yaitu Dasawisma. Melalui dasawisma baik Tim Penggerak PKK Desa, Tim Penggerak PKK Kecamatan maupun dinas terkait dapat dengan mudah menjangkau setiap keluarga yang ada, Tidak terkecuali ibu hamil. Kelompok dasawisma adalah kelompok ibu - ibu yang berasal dari 10 - 20 rumah yang bertetangga untuk mempermudah jalannya satu program. Tujuan dari pembentukan dasawisma ini adalah membantu kelancaran tugas - tugas pokok dan program PKK Desa. Kegiatannya diarahkan pada peningkatan kesehatan keluarga. Beberapa masalah kesehatan yang menjadi jangkauan kerja dari anggota dasawisma adalah usaha perbaikan gizi keluarga, masalah pertumbuhan anak, makanan sehat bagi keluarga, masalah kebersihan lingkungan, masalah bencana dan kegawatdaruratan kesehatan termasuk resikonya, masalah kesehatan ibu, bayi dan balita, dan masalah penyakit.

Keberadaan kelompok-kelompok dasawisma di TP. PKK Desa se - Kecamatan Utan selama ini masih sebesar 27,78\%. Baru di Desa Orong Bawa yang sudah terbentuk dari tahun 2013, sedangkan untuk desa - desa yang lain berjalan sendiri - sendiri tidak lagi dibawah pengawasan Tim Pengerak PKK Desa, hal ini disebabkan karena peran PKK Desa juga tidak berjalan sesuai dengan tugas dan fungsinya.

Langkah - langkah yang dilakukan untuk meningkatkan peran dasawisma di Desa Pukat Kecamatan Utan:

1. Pembentukan kepengurusan dasawisma di Desa Pukat.

2. Peningkatan kapasitas kepengurusan dasawisma di Desa Pukat melalui pelatihan - pelatihan

3. Optimalisasi peran dasawisma di Desa Pukat dengan mengaktifkan peran serta pengurus dasawisma dalam membantu menurunkan angka kematian bayi

Berdasarkan latar belakang masalah tersebut maka peneliti tertarik untuk melakukan penelitian dengan judul "Optimalisasi peran dasawisma dalam menurunkan angka kematian bayi di Desa Pukat Kecamatan Utan".

\section{METODE PENELITIAN}

\section{A. Waktu dan Tempat Penelitian}

Penelitian dilaksanakan dari bulan Desember 2018 sampai bulan Juni 2019 yang dilaksanakan di Desa Pukat dan Desa Orong Bawa Kecamatan Utan Kabupaten Sumbawa. 


\section{B. Populasi dan Sampel}

Populasi adalah keseluruhan subyek penelitian atau obyek yang diteliti (Arikunto 2006). Populasi dalam penelitian ini adalah Ibu hamil yang berada di Desa Pukat dan Desa Orong Bawa Kecamatan Utan Kabupaten Sumbawa. Sedangkan teknik pengambilan sampel adalah total sampling menurut (Sugiono 2007) jumlah populasi yang kurang dari 100 seluruh populasi dijadikan sampel penelitian semuanya, jumlah populasi dalam penelitian ini pada bulan Desember 2018 di desa Pukat berjumlah 102 orang ibu hamil, di Desa Orong Bawa berjumlah 11 orang ibu hamil dan pada bulan Juni 2019 di Desa Pukat berjumlah 86 orang ibu hamil sehingga dalam penelitian teknik pengambilan sampel dengan total sampling.

\section{Teknik Pengumpulan Data}

Pengumpulan data dengan menggunakan teknik :

1. Wawancara (Interview) yaitu Metode mengumpulkan data yang dilakukan melalui wawancara atau tatap muka secara langsung dengan responden.

2. Penyebaran daftar pertanyaan (Questionaire) adalah teknik pengumpulan data yang dilakukan dengan cara mengajukan pertanyaan melalui daftar pertanyaan pada responden terpilih untuk dijawab.

3. Studi dokumentasi yaitu pengumpulan data yang tidak ditujukan langsung kepada subyek penelitian, dokumen yang diteliti dapat berbagai macam tidak hanya dokumen resmi bisa berupa buku harian, surat pribadi, laporan, notulen rapat, catatan kasus (case record) dalam pekerjaan sosial dan dokumen lainnya.

\section{Variabel Penelitian}

Variabel di dalam penelitian merupakan suatu atribut dari sekelompok obyek yang diteliti yang mempunyai variasi antara satu dengan yang lain dalam kelompok tersebut (Sugiono 1997). Variabel adalah merupakan obyek penelitian atau yang menjadi fokus perhatian pada penelitian. Dalam penelitian ini terdapat dua variabel yaitu variabel bebas (independent variable) dan variabel terikat (dependent variable)

1. Variabel bebas adalah variabel yang menjadi sebab timbulnya atau berubahnya variabel terikat. Yang menjadi variabel bebas dalam penelitian ini adalah Peran Dasawisma.

2. Variabel terikat merupakan variabel yang dipengaruhi atau yang menjadi akibat, karena adanya variabel bebas. Yang menjadi variabel terikat dalam penelitian ini adalah menurunnya angka kematian bayi.

\section{E. Analisis Data}

Analisis data yang digunakan dalam penelitian ini adalah deskriftif kualitatif yang bersifat menggambarkan, memaparkan dan menguraikan obyek yang diteliti (Arikunto 2006). Penelitian kualitatif antara lain bersifat diskriptif, data yang dikumpulkan lebih banyak berupa kata - kata atau gambar dari angka - angka. Dengan demikian penelitian deskriftif kualitatif merupakan penelitian yang bermaksud membuat deskripsi atau gambaran untuk memahami fenomena tentang apa yang dialami oleh subyek penelitian misalnya perilaku, persepsi, motivasi, tindakan dan lain-lain (Melong 2010).

\section{F. Instrumen Penelitian}

Menurut Sugiono (2013) Instrumen penelitian adalah suatu alat yang digunakan untuk mengukur fenomena alam maupun sosial yang diamati. Instrumen yang digunakan dalam penelitian ini adalah instrument kuisioner metode tertutup, dimana kemungkinan jawaban sudah ditentukan terlebih dahulu dan responden tidak diberikan alternatif jawaban. Indikator - indikator untuk variabel tersebut dijabarkan oleh penulis menjadi sejumlah pertanyaan sehingga diperoleh data kualitatif. Data ini akan diubah menjadi bentuk kuantitatif dengan pendekatan analisis statistik.

Secara umum teknik dalam pemberian skor yang digunakan dalam kuisioner ini adalah teknik skala likert. Penggunaan skala likert menurut Sugiono (2013) adalah "skala Likert digunakan untuk mengukur sikap, pendapat dan persepsi seseorang atau sekelompok orang tentang fenomena sosial". 
Pada penelitian ini peneliti menggunakan bobot nilai 1 dan 0.1 untuk jawaban benar sesuai dengan harapan peneliti dan 0 untuk jawaban yang salah atau yang tidak sesuai dengan harapan peneliti. Dari perolehan nilai pada masing - masing pertanyaan pada kuisioner maka dapat diprentasekan dengan rumus:

$$
\begin{aligned}
\mathrm{R}=\frac{S P}{S T} \times 100 \% & \\
\text { Keterangan : } \mathrm{R} & =\text { Nilai Persentase } \\
\mathrm{SP} & =\text { Skor Perolehan } \\
\mathrm{ST} & =\text { Skor Ideal atau skor yang diharapkan }
\end{aligned}
$$

Selanjutnya untuk mengetahui faktor - faktor yang sangat berpengaruh terhadap kematian bayi maka digunakan skala prosentase sebagai berikut:

Tabel. 1 Tabel Prosentase Nilai

\begin{tabular}{|c|c|c|c|c|c|}
\hline No. & Aspek & Sub Aspek & $\begin{array}{l}\text { Jumlah } \\
\text { Item }\end{array}$ & $\begin{array}{l}\text { Skor } \\
\text { ideal }\end{array}$ & $\begin{array}{l}\text { Tota } \\
\text { Skor }\end{array}$ \\
\hline \multirow[t]{5}{*}{1} & Faktor Ibu & a. Pemeriksaan kehamilan & 2 & 2 & 13 \\
\hline & & b. Usia kehamilan & 2 & 2 & \\
\hline & & c. Jarak Kelahiran & 3 & 3 & \\
\hline & & d. Asupan makanan ibu hamil & 4 & 4 & \\
\hline & & e. Pengaruh lingkungan & 2 & 2 & \\
\hline \multirow[t]{3}{*}{2} & Faktor Janin & a. Pengetahuan ibu & 5 & 5 & 12 \\
\hline & & b. Keadaan bayi & 5 & 5 & \\
\hline & & c. Keadaan ibu & 2 & 2 & \\
\hline \multirow[t]{4}{*}{3} & $\begin{array}{l}\text { Faktor } \\
\text { Pendukung }\end{array}$ & $\begin{array}{l}\text { a. Pengetahuan tentang } \\
\text { fasilitas kesehatan }\end{array}$ & 2 & 2 & 8 \\
\hline & Pelayanan & b. Fasilitas kesehatan & 2 & 2 & \\
\hline & Kesehatan & $\begin{array}{l}\text { c. Dukungan pemerintah dan } \\
\text { masyarakat }\end{array}$ & 2 & 2 & \\
\hline & & d. Prasarana kesehatan & 2 & 2 & \\
\hline \multirow[t]{3}{*}{4} & Faktor & a. Penolong persalinan & 3 & 3 & 8 \\
\hline & Penolong & b. Kualitas pelayanan & 3 & 3 & \\
\hline & Persalinan & $\begin{array}{l}\text { c. Pengetahuan seputar } \\
\text { persalinan }\end{array}$ & 2 & 2 & \\
\hline \multirow[t]{3}{*}{5} & Peran Ibu - & a. Informasi PKK & 1 & 1 & 6 \\
\hline & ibu Tim & b. Peran PKK & 3 & 7 & \\
\hline & $\begin{array}{l}\text { Penggerak } \\
\text { PKK }\end{array}$ & c. Pengertahuan tentang PKK & 2 & 2 & \\
\hline \multirow[t]{3}{*}{6} & Dasawisma & a. Informasi Dasawisma & 1 & 1 & 6 \\
\hline & & b. Peran Dasawisma & 3 & 7 & \\
\hline & & $\begin{array}{l}\text { c. Pengetahuan tentang } \\
\text { Dasawisma }\end{array}$ & 2 & 2 & \\
\hline
\end{tabular}

\begin{tabular}{cc}
\hline Prosentase Nilai & Kualifikasi \\
\hline $0-24,99$ & Sangat Berpengaruh \\
$25-49,99$ & Berpengaruh \\
$50-74,99$ & Tidak berpengaruh \\
$75-100$ & Sangat Tidak Berpengaruh \\
\hline
\end{tabular}

Faktor penyebab kematian bayi tersebut peneliti rangkum dalam tabel sebagai berikut:

Tabel 2 Faktor - faktor yang mempengaruhi angka kematian bayi

Sumber : Data Primer Hasil Penelitian 2018 


\section{HASIL PENELITIAN DAN PEMBAHASAN}

\section{A. Hasil Penelitian}

\section{Gambaran Umum Dasawisma Desa Orong Bawa dan Desa Pukat}

Dari hasil analisis data dapat dilihat perbandingan antara keadaan dasawisma yang ada di Desa Orong Bawa dan Desa Pukat. Dasawisma di Desa Orong Bawa telah terbentuk sejak tahun 2013, dengan dukungan Pemerintah Desa dan Ibu Ketua Tim Pengerak PKK, dasawisma Di Desa Orong Bawa terus melakukan pemberdayaan kepada masyarakat melalui kegiatan - kegiatan yang melibatkan baik ketua maupun seluruh anggota dasawisma. Sedangkan dasawisma Desa Pukat setelah terbentuk pada tahun 2017 tidak lagi berjalan, sehingga diperlukan langkah - langkah penyegaran kepengurusan agar dapat berjalan optimal sesuai tugas dan fungsinya.

Langkah - langkah penyegaran kepengurusan dasawisma di Desa Pukat adalah :

a. Sosialisasi pembentukan kembali atau penyegaran kelompok dasawisma dengan mengundang Kepala Dusun beserta Ketua PKK Dusun, Ketua RT beserta Ketua PKK RT, Tokoh Agama, Tokoh Masyarakat, Kader Posyandu, Kader PPKBD, Kader Sub PPKBD dan Bidan Desa dengan Nara Sumber dari Tim Penggerak PKK Kecamatan.

b. Musyawarah desa dalam rangka menggerakkan semua stakeholders yang dihadiri oleh TP. PKK Desa, Kepala Dusun dan Ketua RT yang difasilitasi oleh Kepala Desa dan Tim Penggerak PKK Desa

c. Musyawarah Dusun dengan mengundang Ketua RT dan Tim Pengerak PKK RT guna menyepakati pembentukan dasawisma dan menyepakati jumlah rumah tangga yang akan masuk dalam kelompok dasawisma.

d. Musyawarah dasawisma yang dihadiri oleh Ketua RT, PKK dan Pokmas melakukan pertemuan untuk memilih Ketua Kelompok dan Sekretaris dasawisma.

e. Kepengurusan dasawisma ditetapkan dengan Keputusan Kepala Desa.

f. Dalam rangka mengoptimalkan peran dasawisma yang telah dibentuk beberapa program peningkatan kapasitas Ketua dan Sekretaris kelompok dasawisma antara lain:

g. Melakukan pelatihan pengurus dasawisma untuk memperkuat tugas dan fungsi dasawisma dengan nara sumber Tim PKK Kecamatan

h. Mengevaluasi agenda kegiatan Dasawisma yang telah disusun oleh Tim Penggerak PKK Kecamatan bersama Tim Penggerak PKK Desa

i. Melakukan follow up dan monitoring terhadap kegiatan dasawisma oleh Tim Penggerak PKK Kecamatan bersama Tim Penggerak PKK Desa

j. Melakukan Pelatihan Program Perencanaan Persalinan dan Pencegahan Komplikasi (P4K) oleh Tim Promosi Kesehatan Ibu dan Anak UPT Puskesmas Utan

Selain kegiatan - kegiatan peningkatan kapasitas Ketua dan Sekertaris, dasawisma Desa Pukat juga melakukan kegiatan - kegiatan yang bersifat memberdayakan anggota - anggota dasawima baik dalam hal peningkatan pengetahuan maupun peningkatan ekonomi ibu - ibu anggota dasawisma. Kegiatan - kegiatan tersebut adalah:

a. Menyampaikan informasi kepada Ibu - ibu hamil seputar kehamilan yang sehat, melahirkan yang aman, menyusui bayi dan perawatan bayi yang benar.

b. Mendorong lbu - ibu hamil anggota dasawisma untuk aktif di kelas ibu hamil yang dilaksanakan oleh Bidan Desa.

c. Mendorong Ibu - ibu hamil untuk aktif di kegiatan posyandu yang dilaksanakan setiap bulan.

d. Memfasilitasi lbu - ibu hamil untuk rutin memeriksakan kehamilannya.

e. Mendorong Ibu - ibu hamil untuk aktif di kegiatan - kegiatan yang dilaksanakan oleh PKK Desa dan Dasawisma 


\section{Faktor - faktor yang mempengaruhi angka kematian bayi di Desa Orong Bawa dan Desa Pukat}

Berdasarkan hasil olah data, dapat dilihat perbandingan keadaan dasawisma Desa Orong Bawa dan Desa Pukat, perbandingan beberapa Deskripsi demografi Ibu hamil di Desa Orong Bawa dan Desa Pukat dan data - data hasil analisis yang mempengaruhi angka kematian bayi baik di Desa Orong Bawa maupun Desa Pukat dapat dilihat pada tabel 1

Tabel 1. Perbandingan Faktor - Faktor Yang Mempengaruhi Angka Kematian Bayi di Desa Orong Bawa dan Desa Pukat

\begin{tabular}{|c|c|c|c|c|c|c|}
\hline \multirow[b]{2}{*}{ No } & \multirow[b]{2}{*}{ Aspek } & \multirow[b]{2}{*}{ Sub Aspek } & \multicolumn{2}{|c|}{ Desa Orong Bawa } & \multicolumn{2}{|c|}{ Desa Pukat } \\
\hline & & & $\begin{array}{l}\text { Total } \\
\text { Skor }\end{array}$ & Kualifikasi & $\begin{array}{l}\text { Total } \\
\text { Skor }\end{array}$ & Kualifikasi \\
\hline & Faktor Janin & $\begin{array}{l}\text { Pengetahuan } \\
\text { ibu }\end{array}$ & 83,6 & $\begin{array}{l}\text { Sangat tidak } \\
\text { berpengaruh }\end{array}$ & 49,6 & Berpengaruh \\
\hline 2 & $\begin{array}{l}\text { Faktor Pendukung } \\
\text { Pelayanan Kesehatan }\end{array}$ & $\begin{array}{l}\text { Pengetahuan } \\
\text { ibu tentang } \\
\text { fasilitas } \\
\text { kesehatan }\end{array}$ & 59,1 & $\begin{array}{c}\text { Tidak } \\
\text { berpengaruh }\end{array}$ & 10,8 & $\begin{array}{c}\text { Sangat } \\
\text { berpengaruh }\end{array}$ \\
\hline 3 & $\begin{array}{l}\text { Faktor Pendukung } \\
\text { Pelayanan Kesehatan }\end{array}$ & $\begin{array}{l}\text { Dukungan } \\
\text { pemerintah dan } \\
\text { masyarakat }\end{array}$ & 100,0 & $\begin{array}{l}\text { Sangat tidak } \\
\text { berpengaruh }\end{array}$ & 49,0 & Berpengaruh \\
\hline 4 & $\begin{array}{l}\text { Peran Ibu - ibu Tim } \\
\text { Penggerak PKK }\end{array}$ & Peran PKK & 71,4 & $\begin{array}{c}\text { Tidak } \\
\text { Berpengaruh }\end{array}$ & 42,9 & Berpengaruh \\
\hline & Dasawisma & $\begin{array}{l}\text { Informasi } \\
\text { Dasawisma }\end{array}$ & 100,0 & $\begin{array}{l}\text { Sangat tidak } \\
\text { berpengaruh }\end{array}$ & 15,7 & $\begin{array}{c}\text { Sangat } \\
\text { berpengaruh }\end{array}$ \\
\hline & Dasawisma & $\begin{array}{l}\text { Peran } \\
\text { Dasawisma }\end{array}$ & 71,4 & $\begin{array}{c}\text { Tidak } \\
\text { Berpengaruh }\end{array}$ & 42,9 & Berpengaruh \\
\hline & Dasawisma & $\begin{array}{l}\text { Pengetahuan } \\
\text { tentang } \\
\text { Dasawisma }\end{array}$ & 100,0 & $\begin{array}{l}\text { Sangat Tidak } \\
\text { berpengaruh }\end{array}$ & 15,7 & $\begin{array}{c}\text { Sangat } \\
\text { berpengaruh }\end{array}$ \\
\hline
\end{tabular}

Dari Tabel 1 Diatas dapat dilihat bahwa di Desa Pukat dari beberapa item pertanyaan yang dikelompokkan yang menurut hasil analisis di Desa Pukat dinyatakan berpengaruh terhadap angka kematian bayi tetapi di Desa Orong Bawa Tidak Berpengaruh. Pengetahuan Ibu akan seputar masalah perkembangan janin minim sehingga mempengaruhi angka kematian bayi, pengetahuan ibu seputar fasilitas kesehatan yang ada juga sangat minim sehingga sangat berpengaruh terhadap angka kematian bayi, sedangkan peran PKK dan Dasawisma di Desa Pukat juga minim sehingga peran serta dalam menekan akan kematian bayi berpengaruh terhadap tingginya angka kematian bayi. Sedangkan keberadaan dan fungsi dasawisma yang sangat minim membuat peran dasawisma sangat berpengaruh terhadap semakin tingginya angka kematian bayi. 
Tabel 2. Rangkuman faktor - faktor yang mempengaruhi angka kematian bayi di Desa Pukat sebelum dilakukan strategi optimalisasi dasawisma dan setelah dilakukan strategi optimalisasi dasawisma

\begin{tabular}{|c|c|c|c|c|}
\hline \multirow[t]{2}{*}{ NO } & \multirow[t]{2}{*}{ Aspek } & \multirow[t]{2}{*}{ Sub Aspek } & $\begin{array}{c}\text { Desa Pukat sebelum } \\
\text { dilakukan strategi } \\
\text { optimalisasi dasawisma }\end{array}$ & $\begin{array}{c}\text { Desa Pukat setelah } \\
\text { dilakukan strategi } \\
\text { optimalisasi } \\
\text { dasawisma }\end{array}$ \\
\hline & & & $\begin{array}{l}\text { Total Kualifikasi } \\
\text { Skor } \quad \text { Ku }\end{array}$ & $\begin{array}{l}\text { Total } \\
\text { Skor }\end{array}$ \\
\hline 1 & Faktor Janin & Pengetahuan ibu & 49,6 Berpengaruh & $\begin{array}{r}95,1 \text { Sangat tidak } \\
\text { berpengaruh }\end{array}$ \\
\hline 2 & $\begin{array}{l}\text { Faktor Pendukung } \\
\text { Pelayanan Kesehatan }\end{array}$ & $\begin{array}{l}\text { Pengetahuan ibu } \\
\text { tentang fasilitas } \\
\text { kesehatan }\end{array}$ & 10,8 Sangat berpengaruh & $\begin{array}{r}95,9 \text { Sangat tidak } \\
\text { berpengaruh }\end{array}$ \\
\hline 3 & $\begin{array}{l}\text { Faktor Pendukung } \\
\text { Pelayanan Kesehatan }\end{array}$ & $\begin{array}{l}\text { Dukungan } \\
\text { pemerintah dan } \\
\text { masyarakat }\end{array}$ & 49,0 Berpengaruh & $\begin{array}{r}100,0 \text { Sangat tidak } \\
\text { berpengaruh }\end{array}$ \\
\hline 4 & $\begin{array}{l}\text { Peran Ibu - ibu Tim } \\
\text { Penggerak PKK }\end{array}$ & Peran PKK & 42,9 Berpengaruh & $\begin{array}{l}85,7 \text { Sangat tidak } \\
\text { berpengaruh }\end{array}$ \\
\hline 5 & Peran Dasawisma & $\begin{array}{l}\text { Informasi } \\
\text { Dasawisma }\end{array}$ & 15,7 Sangat berpengaruh & $\begin{array}{r}100 \begin{array}{r}\text { Sangat tidak } \\
\text { berpengaruh }\end{array} \\
\end{array}$ \\
\hline 6 & Peran Dasawisma & Peran Dasawisma & 42,9 Berpengaruh & $\begin{aligned} & 72,8 \text { Tidak } \\
& \text { Berpengaruh } \\
&\end{aligned}$ \\
\hline 7 & Peran Dasawisma & $\begin{array}{l}\text { Pengetahuan } \\
\text { tentang Dasawisma }\end{array}$ & 15,7 Sangat berpengaruh & $\begin{array}{l}100 \begin{array}{l}\text { Sangat tidak } \\
\text { berpengaruh }\end{array}\end{array}$ \\
\hline
\end{tabular}

Sumber : Data primer hasil penelitian 2019

Dari Tabel 2 dapat dilihat rangkuman faktor - faktor yang berpengaruh maupun sangat berpengaruh terhadap tingginya angka kematian bayi di Desa Pukat setelah dilakukan intervensi tidak ada lagi.

Setelah dilakukan intervensi melalui optimalisasi peran dasawisma di Desa Pukat Angka Kematian bayi di Desa Pukat sampai dengan bulan Juni 2019 terdapat 1 kematian bayi yang terjadi pada bulan April 2019. Jika dibandingkan pada bulan yang sama pada tahun 2018 terjadi penurunan angka kematian bayi yang cukup signifikan yaitu dari 6 Kematian Bayi menjadi 1 Kematian Bayi.

\section{KESIMPULAN}

Berdasarkan hasil penelitian yang dilaksanakan dapat disimpulkan bahwa :

1. Telah dilakukkan penyegaran Kepengurusan dasawisma di Desa Pukat Kecamatan Utan melalui langkah-langkah :

a. Sosialisasi pembentukan kembali atau penyegaran kelompok dasawisma dengan mengundang Kepala Dusun beserta Ketua PKK Dusun, Ketua RT beserta Ketua PKK RT, Tokoh Agama, Tokoh Masyarakat, Kader Posyandu, Kader PPKBD, Kader Sub PPKBD dan Bidan Desa dengan Nara Sumber dari Tim Penggerak PKK Kecamatan.

b. Musyawarah desa dalam rangka menggerakkan semua stakeholders yang dihadiri oleh TP. PKK Desa, Kepala Dusun dan Ketua RT yang difasilitasi oleh Kepala Desa dan Tim Penggerak PKK Desa

c. Musyawarah Dusun dengan mengundang Ketua RT dan Tim Pengerak PKK RT guna menyepakati pembentukan dasawisma dan menyepakati jumlah rumah tangga yang akan masuk dalam kelompok dasawisma. 
d. Musyawarah dasawisma yang dihadiri oleh Ketua RT, PKK dan Pokmas melakukan pertemuan untuk memilih Ketua Kelompok dan Sekretaris dasawisma.

e. Kepengurusan dasawisma ditetapkan dengan Keputusan Kepala Desa.

2. Optimalisasi Peran Dasawisma di Desa Pukat sudah dilaksanakan melalui strategi-strategi dengan kegiatan :

a. Melakukan pendekatan dengan Bapak Kades dan Ibu kades sebagai Ketua Tim Penggerak PKK Desa Pukat untuk lebih memperhatikan dan mendukung keberadaan Dasawisma

b. Melakukan penyegaran pengurus dengan melibat Ketua RT beserta Istri, Ketua RW Beserta Istri, Kepala Dusun Beserta Istri, Kader Posyandu, Kader PPKBD, Kader Sub PPKBD dan Bidan Desa untuk terut serta berperan aktif dalam kepengurusan dan kegiatan Dasawisma

c. Melakukan pelatihan pengurus dasawisma untuk memperkuat tugas dan fungis dasawisma

d. Menyusun agenda kegiatan Dasawisma

e. Melakukan follow up dan monitoring terhadap kegiatan dasawisma

f. Melakukan Pelatihan Program Perencanaan Persalinan dan Pencegahan Komplikasi (P4K)

3. Optimalisasi peran dasawisma desa pukat dapat dilihat dari keberhasilan dalam mempengaruhi penurunan angka kematian bayi melalui pengetahuan ibu, dukungan pemerintah dan masyarakat, peran PKK, Informasi Dasawisma, Peran Dasawisma dan Pengetahuan tentang Dasawisma. Angka Kematian bayi di Desa Pukat priode bulan Januari 2019 sampai dengan bulan Juni 2019 terdapat 1 kematian bayi. Jika dibandingkan pada priode yang sama tahun 2018 terjadi penurunan angka kematian bayi yang cukup signifikan yaitu dari 6 Kematian Bayi menjadi 1 Kematian Bayi.

\section{DAFTAR PUSTAKA}

Arikunto, S. 2006. Metode Penelitian Kualitatif. Jakarta: Bumi Aksara

Benson, and Martin, 2009. Buku Saku Obstetri \& Ginekologi. Penerbit Buku Kedokteran EGC, Jakarta.

Clarence, W., Gowen, Jr., 2014. Kedokteran Fetal dan Neonatal. Dalam Nelson IImu Kesehatan Anak esensial. (Editor) Lily, R,. Rosalina, R,. Elsevier (Singapore) Pte.Ltd.

Craig, G dan Mayo, M. 1995. Community Empowerment: a reader in participation and Development. London, Biddles Ltd.

Departemen Pendidikan Nasional RI. 1995. Kamus Besar Bahasa Indonesia. Jakarta

Dinas Kesehatan Kabupaten Sumbawa, 2015. Profil Kesehatan Kabupaten Sumbawa Tahun 2014 Kementerian Kesehatan. Dinas Kesehatan Kabupaten Sumbawa, Sumbawa.

Irawan, Prasetya. 2016. Penelitian Kualitatif dan Kuantitatif untuk IImu - ilmu Sosial. Departemen ilmu administrasi Fisip Universitas Indonesia

Komarudin. 1994. Ensiklopedia Muslim. Edisi keenam. Penerbit BumiAksara, Jakarta

Machfud Sidik. (2002). Optimalisasi Pajak Daerah dan Retribusi Daerah Dalam Rangka Meningkatkan Kemampuan Keuangan Daerah, www.mepugm.ac.id

Melong Lexy. 2010. Metode Penelitian Kualitatif. Bandung: PT Remaja Rosdakarya

Miles, Matthew B., dan A. Michael Huberman. 1992. Analisis Data Kualitatif.

Universitas Indonesia Pers, Jakarta.

Prawirohardjo, S. 2009. Buku Acuan Nasional Pelayanan Keshatan Maternal dan Neonatal. PT Bina Pustaka Sarwono Prawirohardjo.

Rappaport, Roy A. Ecology, Meaning, and Religion. Richmond: North Atlantic Books 1979.

RCPI and HSE. Investigation and Management of Late Fetal Intrauterine Death and Stillbirth. RCPI HSE [Internet].2011 [diakses pada tanggal 10 Juni 2017] 2011; (4). Tersedia di: http://www.rcpi.ie/content/docs/000001/668_5_media.pdf

Rosna Hadi Hadi. 2014. Peran Dasawisma dalam Membina Status Gizi Balita di Desa Pilomonu Kecamatan Mootilango Kabupaten Gorontalo, Gorontalo

Susanto, Agus. 2017. Peran kader posyandu sebagai agen perubahan perilaku pada ibu hamil dalam upaya menekan angka kematian ibu dan bayi. Vol. 2 No.1. Tegal: Politeknik Harapan Bersama 
Sugiyono. 2013. Metode Penelitian Pendidikan Pendekatan Kuantitatif, Kualitatif, dan R\&D. Bandung: Alfabeta

Sugiyono. (2007). Metode Penelitian Binis, Cetakan Kesepuluh, CV Alfabeta, Bandung.

Sugiono. 2005. Memahami Penelitian Kualitatif. Alfabeta, Bandung . 2011. Metode Penelitian Kuantitatif Kualitatif dan R Dan D. Alfabeta, Bandung. . (1997). Metodologi Penelitian Administrasi. Yogjakarta: CV Alfabeta.

Soekanto Soerjono. Sosiologi Suatu Pengantar. Jakarta: Rajawali Pers, 2012. 2009. Sosiologi Suatu Pengantar. Edisi Baru: Rajawali Pers.Jakarta.

Winardi. 1996. Azas - Azas Marketing. Alumni. Bandung.

Yin, K. Robert. 2014. Studi kasus desain dan metode. Raja Grafindo Persada Jakarta

Yustika, A. Erani. 2010. Ekonomi Kelembagaan. Defenisi, Teori dan Strategi.

Banyumas Publishing. Malang 